\title{
Landscape Connectivity Shapes the Spread Pattern of the Rice Water Weevil: A Case Study from Zhejiang, China
}

\author{
Zhengjun Wang · Jianguo Wu • Hanwu Shang • \\ Jiaan Cheng
}

Received: 6 April 2010/Accepted: 16 November 2010/Published online: 18 December 2010

(C) Springer Science+Business Media, LLC 2010

\begin{abstract}
The spread of invasive species is a complex ecological process that is affected by both the biology of the species and the spatial structure of a landscape. The rice water weevil (Lissorhoptrus oryzophilus Kuschel), a notorious crop pest found in many parts of the world, is one of the most devastating invasive species in China, and has caused enormous economic losses and ecological damage. Little is known, however, as to how habitat and landscape features affect the spatial spread of this pest. Thus, the main goal of this study was to investigate the relationship between the observed spread pattern of L. oryzophilus and landscape structural factors in Zhejiang Province, China between 1993 and 2001. We quantified the invasive spread of the weevil in terms of both the proportion of infected area and spread distance each year as well as landscape structure and connectivity of rice paddies with landscape metrics. Our results
\end{abstract}

\section{Z. Wang}

College of Life Sciences, Capital Normal University,

Beijing 100048, China

J. Wu

School of Life Sciences and Global Institute of Sustainability,

Arizona State University, Tempe, AZ 85287, USA

J. Wu

Sino-US Center for Conservation, Energy and Sustainability

Science (SUCCESS), Inner Mongolia University, Hohhot,

Inner Mongolia 010021, China

H. Shang ( $\square)$

College of Life Science, China Jiliang University,

Hangzhou 310018, China

e-mail: Hanwush@yeah.net

J. Cheng

Institute of Applied Entomology, Zhejiang University,

Hangzhou 310029, China showed that the spread of L. oryzophilus took place primarily in the southwest-northeast direction along coastal areas at a speed of about $36 \mathrm{~km}$ per year. The composition and spatial arrangement of landscape elements were key determinants of this unique spread pattern. In particular, the connectivity of early rice paddies was crucial for the invasive spread while other factors such as meteorological and geographical conditions may also have been relevant. To control the spread of the pest, we propose four management measures: (1) to implement a landscape-level planning scheme of cropping systems to minimize habitat area and connectivity for the pest, (2) to reduce the source populations at a local scale using integrated control methods, (3) to monitor and report invasive spread in a timely manner, and (4) to strengthen the quarantine system. To be most effective, all four management measures need to be implemented together through an integrated, multi-scaled approach.

Keywords The rice water weevil - Biological invasion Landscape connectivity - Invasive spread · Pest control . China

\section{Introduction}

Numerous studies have shown that the composition and spatial arrangement of landscape elements can significantly influence ecological processes (Turner 1989; Wu and Hobbs 2002). One such example is the interaction between the spatial structure of habitat patches and the dispersal of invasive species in heterogeneous landscapes (With 2002; Maheu-Giroux and Blois 2007; Nesslage and others 2007). The spread and distribution of invasive species are often affected directly by the habitat suitability and spatial configuration of landscape patches (Clifford and others 2002; 
Zhu and others 2007; Sebert-Cuvillier and others 2008; Thiele and others 2008).Suitability of patches for animal movement usually depends on the availability of food resources and accessibility for a particular species. Overall, the connectivity between all suitable patches is a key determinant of the spread of invasive species across a landscape (Wiens and others 1997; Haddad 2000; Collinge 2000; Crowl and others 2008).

Thus, it is necessary to quantify landscape patternwhich includes both the composition and configuration of landscape elements - in our attempt to understand and predict the spatial spread of invasive species. Landscape metrics, a group of synoptic indices that characterize various aspects of landscape pattern, have widely been used (McGarigal and others 2002; Wu 2004).Of several dozen landscape metrics, the total amount, patch size, and connectivity of habitat are frequently found to be important for explaining ecological dynamics in fragmented landscapes (Wu 2009).Landscape connectivity has been measured either structurally or functionally (Brett 2003).Structural connectivity measures the degree of connectedness in the physical structure of a landscape, without direct consideration of a particular ecological process (e.g., animal movement or invasive species spread). Functional connectivity integrates both landscape structural connectedness and the dispersal ability of the organisms under consideration, which is more appropriate for studying invasive spread or animal movement behavior in general (Andreassen and others 1996; Pither and Taylor 1998; Brooker and others 1999; $\mathrm{Li}$ and $\mathrm{Wu} 2004$ ).

The rice water weevil, Lissorhoptrus oryzophilus Kuschel, is a formidable crop pest in many parts of the world because of its parthenogenetic behavior and abilities to spread and adapt to new habitat. The pest originated in the United States (Zhao and others 1996; Chen and others 2005), and was introduced into Japan in 1976 (Iwata 1976)and then Korea and North Korea in the 1980s (Goh and Choi 1993).The first reported case of the rice water weevil in China was from Tangshan, Hebei Province in the northern part of the country in 1988 (Chen and others 2005).Since then the pest spread quickly across a dozen provinces of China at a speed of $1-30 \mathrm{~km} / \mathrm{yr}$, and infected more than 400,000 ha of crop fields by the late 1990s (Shang and Zhai 1997; Chen and others 2005).As one of the most devastating invasive species in China, $L$. oryzophilus has caused enormous economic losses and ecological damages (Wei 1997; Guo 1996; Shang and others 2003; Chen and others 2005).

Although several studies have investigated the spatial distribution of the pest on broad scales across the country and specific control mechanisms at local scales (e.g., Shang and Zhai 1997; Shang and others 2003; Chen and others 2005), it is poorly understood how habitat and landscape features affect the spread of this invasive beetle on multiple spatial scales. The main objectives of this study, therefore, were to quantify the spread pattern of L. oryzophilus in Zhejiang Province in southern China between 1993 and 2001, and explore landscape structural factors responsible for the observed spread pattern. A better understanding of the spread mechanisms in relation to landscape pattern is certainly necessary to improve management practices to prevent and control the invasion of the rice water weevil.

\section{Methods}

Study Area

The study area is Zhejiang Province, located in the southeast of China (Fig. 1a, b), which has a typical subtropical monsoon climate with an average annual temperature of $17^{\circ} \mathrm{C}$ and an average annual precipitation of $1319.7 \mathrm{~mm}$. The rainy season typically lasts from early

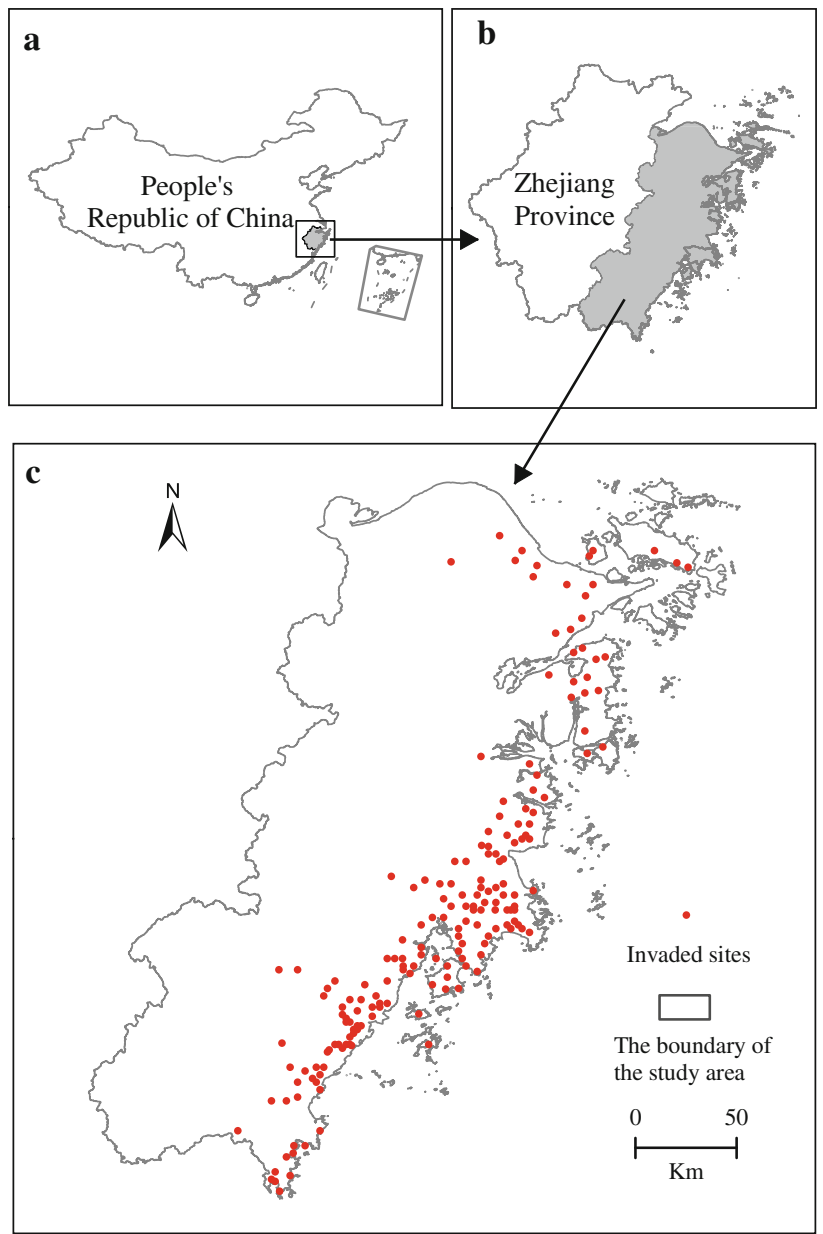

Fig. 1 Location map of the study area in Zhejiang Province, China (a and b) and the distribution of invaded sites from 1993 to 2001 (c) 
June to early July. The western and southern parts of this area are dominated by mountains and hills, whereas areas near the coastline are lowland plains mostly cultivated with rice paddies. The occurrence of the rice water weevil in Zhejiang Province was first spotted by a farmer in Yuhuan County in 1993. Field surveys later revealed that infestations were present in 31 villages and towns in that county in 1993. The pest invaded 23 counties (including 182 villages and towns) from 1993 to 2001 (Fig. 1c).

\section{Data Collection}

The symptoms of infected crops and spatial distribution of the rice water weevil were surveyed by trained local experts each year between 1993 and 2001 (Chinese National Agricultural Technical Extension Service Center 1998).The survey records include the number of villages and towns invaded by the pest, as well as the specific locations of invaded areas of the early- and late-planted rice paddies (double cropping in the same year) in each village and town. Here, the early-planted rice (thereafter termed "the early rice") refers to the rice that is planted in the first cropping season each year. The early rice matures earlier because its growth period is shorter. The rice water weevil has two generations in a single year in the study area, but only the larvae of the first generation infest the early rice (Lin and Zhao 1998; Zhai and others 1997).Thus, this study focuses on the data of early rice (Fig. 1c). In addition, we also acquired spatial data on administrative boundaries, roads, elevation (Digital Elevation Model- based maps), and distribution of rice fields in Zhejiang Province. All spatial data were represented as maps at the scale of 1:500,000. The spatial distribution of earlyrice paddies was rasterized at the spatial resolution of $100 \times 100 \mathrm{~m}$ using ArcGIS 9.2 for the purpose of computing landscape metrics.

\section{Spatial Analysis}

We quantified the spread of the rice water weevil in terms of both the proportion of invaded area and spread distance each year. The proportion of invaded area was computed as the ratio of the invaded area to the total area of the earlyrice paddies each year. To calculate the spread distance each year, we first determined the primary directions of the spread of the invasive insect since 1993 using linear regression based on the values of $\mathrm{x}$ and $\mathrm{y}$ coordinates for all invaded locations (villages and towns and thereafter termed "invaded sites"). The regression line indicated two primary spread directions: northeastward and southwestward (Fig. 2b). A third direction (northwestward) was represented by the line perpendicular to the regression line. This method was based on our empirical observation that the spread pattern since 1993 were primarily in these three directions (Fig. 2a, b). The spread distance each year was then computed along each direction as the distance between the furthermost invaded sites in two consecutive years in that direction. Regression and correlation analysis were conducted using SPSS 13.
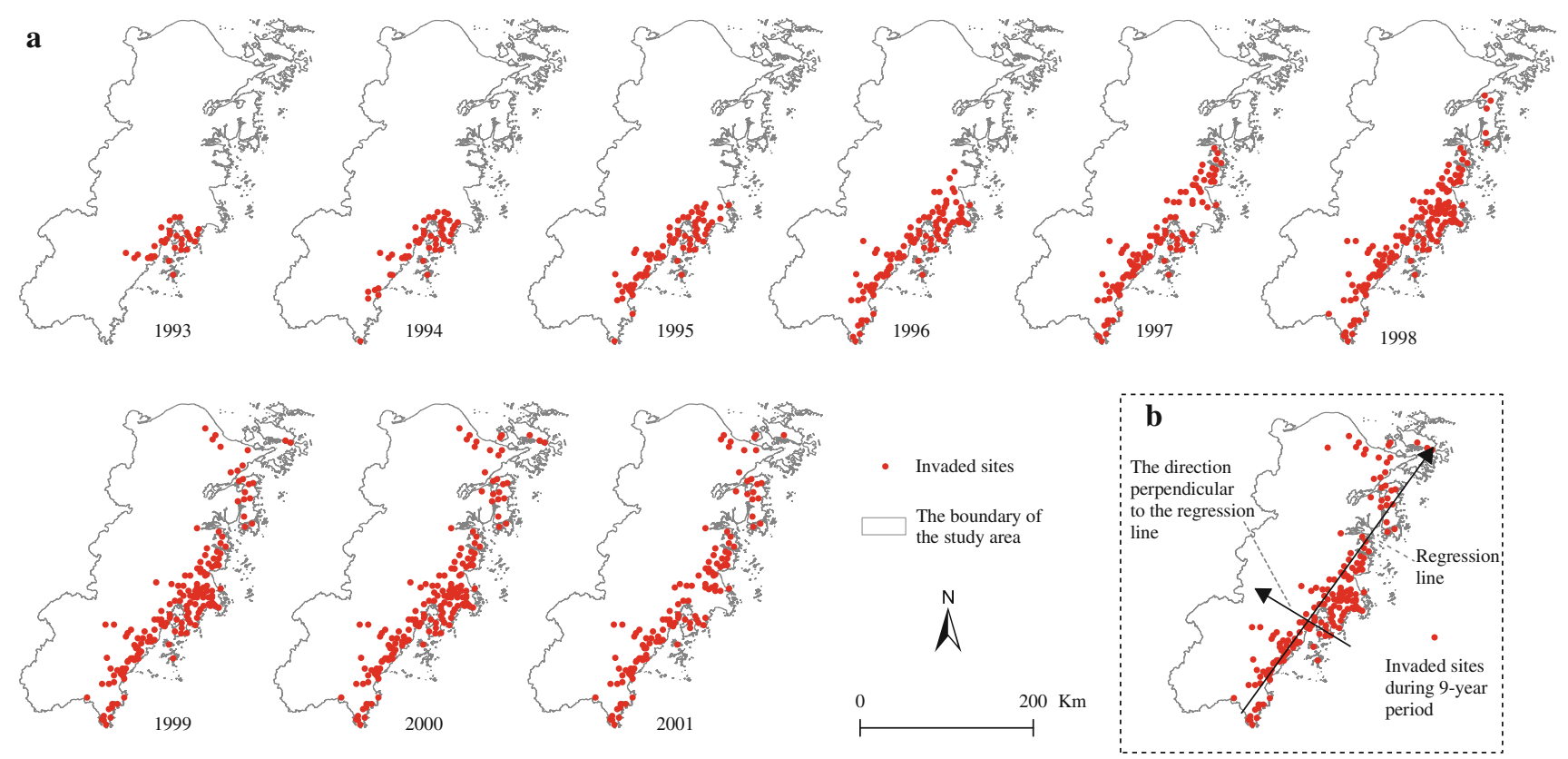

Fig. 2 Time series of spread pattern of L. oryzophilus in early rice fields in Zhejiang Province from 1993 to 2001 (a). The inset illustrates the primary directions of the invasive spread during the 9-year period (b) 
Fig. 3 Illustration of the six transects along the coast-toinland direction for computing landscape metrics. The dark areas are early rice paddies in 1999, and areas labeled as "a" represent single-season rice cropping fields. The serial number of grid cells (1 through 6) increases from costal to inland areas

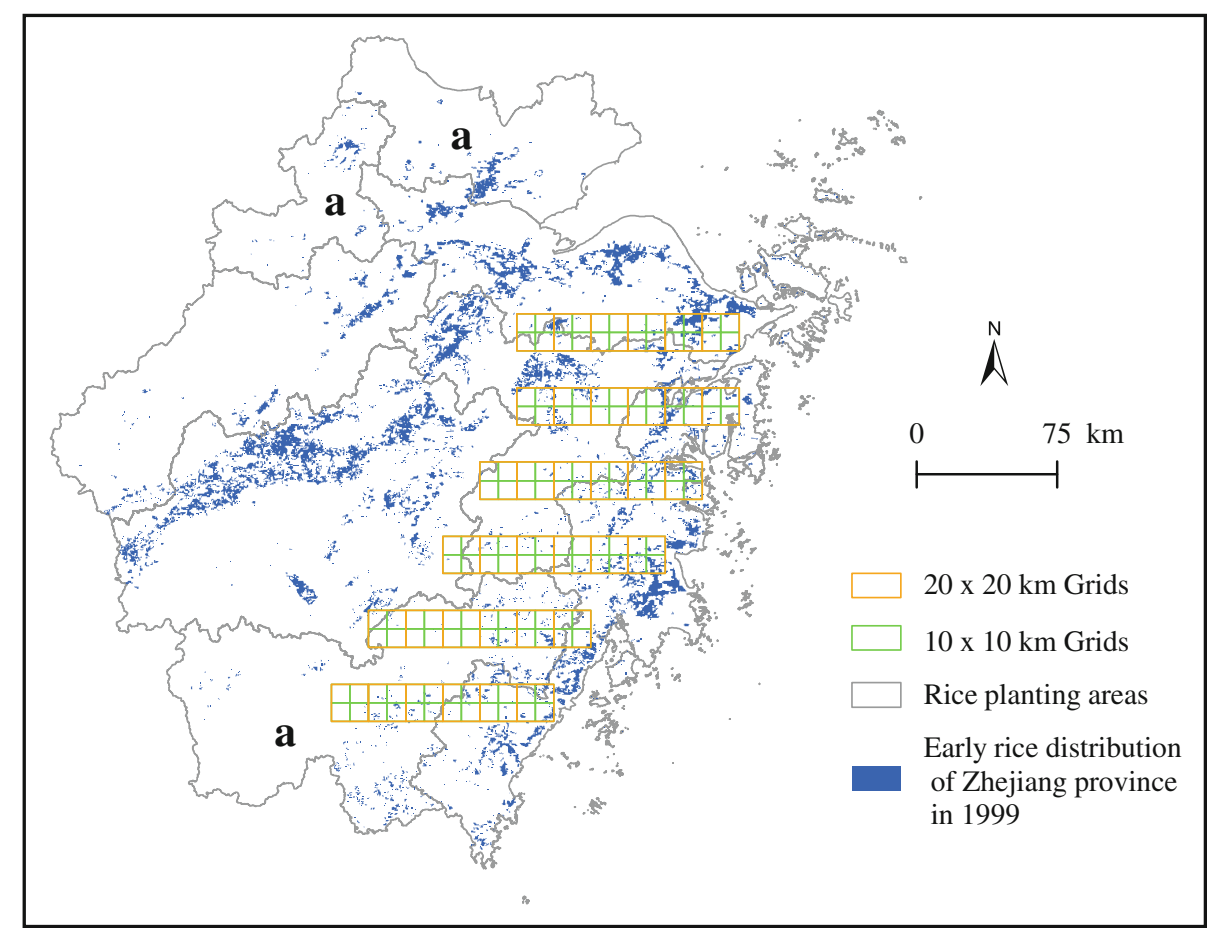

To quantify landscape structure and connectivity of rice paddies from the coast to inland areas, we selected six eastwest transects following the method outlined in Luck and $\mathrm{Wu}$ (2002).Each transect was $20 \times 120 \mathrm{~km}$ and the distance between two adjacent transects was $20 \mathrm{~km}$ apart (Fig. 3).We computed the following three landscape metrics along each transect as per McGarigal and others (2002):

(1) Percentage of Landscape (PLAND), which is the areal percentage of a patch type relative to the entire landscape. It was calculated as:

PLAND $_{i}=\frac{\sum_{j=1}^{n} \mathrm{a}_{i j}}{\mathrm{~A}}(100)$,

where $\mathrm{a}_{i j}\left(\mathrm{~m}^{2}\right)$ is the area of the $j$ th patch of type $i, n$ is the number of patches of type $i$, and $\mathrm{A}\left(\mathrm{m}^{2}\right)$ is the landscape area.

(2) Mean patch size (MPS), which is the average area of all patches of a certain type in a landscape, calculated as:

$M P S=\frac{A_{i}}{n_{i}}$,

where $A_{i}\left(\mathrm{~m}^{2}\right)$ is the total area of patch type $i$, and $n_{i}$ is the number of patches of type $i$ in the landscape.

(3) Connectance (CONNECT), which is the number of functional joinings among all patches of a patch type of interest for a given threshold distance value divided by the total number of possible joinings among all patches of the corresponding patch type, multiplied by 100 to convert to a percentage. The formula for calculation is:

CONNECT $=\left[\begin{array}{l}\sum_{j=k}^{n} c_{i j k} \\ \frac{n_{i}\left(n_{i}-1\right)}{2}\end{array}\right](100)$,

where $\mathrm{c}_{i j k}$ is the joining between patchs $j$ and $k(0=$ unjoined, $1=$ joined) of the patch type $i, n_{i}$ is the number of patches of patch type $i$. We set the threshold distance to $2 \mathrm{~km}$ based on the empirically observed flight distance of L. oryzophilus.

The patch type used in computing the above three landscape metrics refers specifically to the patches of earlyrice paddies. To address the potential problem of scale effects (Luck and Wu 2002; Wu 2004),we computed these landscape metrics at two grid cell sizes: $20 \times 20 \mathrm{~km}$ (i.e., dividing each transect into six $20 \times 20 \mathrm{~km}$ grid cells) and $10 \times 10 \mathrm{~km}$ (i.e., dividing each transect into twenty-four $10 \times 10$ grid cells) (Fig. 3). In the calculation of CONNECT, we set the threshold distance to $2 \mathrm{~km}$ which corresponded to the dispersal distance of $L$. oryzophilus (Zhai and others 1997).Landscape pattern analysis was conducted using ArcGIS 9.2 and Fragstats 3.3 (McGarigal and others 2002). 


\section{Results}

\section{Spatial Pattern of the Rice Water Weevil Invasion}

The spread of L. oryzophilus population took place primarily along the coastal areas between 1993 and 2001 (Fig. 2; Table 1). During this period of time, the invasive species spread $90.68 \mathrm{~km}$ southwestward, $202.9 \mathrm{~km}$ northeastward, and $57.21 \mathrm{~km}$ northwestward (Fig. 2a; Table 2).The total spread distance along the southwest-northeast axis was $293.58 \mathrm{~km}$, which was much greater than that in the inland direction. The number of villages and towns invaded increased from 31 to 172 , and the total area invaded increased from $117 \mathrm{~km}^{2}$ in $1993-406.4 \mathrm{~km}^{2}$ in 1998 and then decreased to $234 \mathrm{~km}^{2}$ in 2001 . The ratio of the invaded area to the total area of early rice, however, continued to increase throughout the 9-year period because the decrease in the invaded area corresponded to a faster decline in the area of early rice between 1998 and 2001 (Table 1). Our correlation analysis also indicated that the invaded area was correlated with the early rice area $(r=0.54$, one-tailed probability $=0.066$ ).

\section{Landscape and Habitat Structural Patterns}

As mentioned in the Methods section, we quantified landscape and habitat patterns at two different sizes of grid cells (i.e., the windows selected for calculating pattern indices as indicated in Fig. 3). At the $20 \times 20 \mathrm{~km}$ window size, the average value of PLAND (the ratio of the early rice area to the total landscape area) for the six transects was $5.6 \%$, indicating that the areal percentage of early rice was low in

Table 1 Changes in the area of early rice, the area of late rice, and the area invaded by the rice water weevil from 1993 to 2001 in Zhejiang Province

\begin{tabular}{lccllr}
\hline Year & $\begin{array}{l}\text { Area of early } \\
\text { rice }\left(\mathrm{km}^{2}\right)\end{array}$ & $\begin{array}{l}\text { Area of late } \\
\text { rice }\left(\mathrm{km}^{2}\right)\end{array}$ & $\begin{array}{l}\text { Invaded } \\
\text { area }\left(\mathrm{km}^{2}\right)\end{array}$ & $\begin{array}{l}\text { Area } \\
\text { ratio }\end{array}$ & $\mathrm{N}$ \\
\hline 1993 & 791.8 & 891.7 & 117.0 & 0.15 & 31 \\
1994 & 846.0 & 953.7 & 135.0 & 0.16 & 49 \\
1995 & 922.3 & 1059.1 & 163.2 & 0.18 & 75 \\
1996 & 978.3 & 1172.9 & 248.1 & 0.25 & 105 \\
1997 & 1205.2 & 1296.5 & 243.2 & 0.20 & 109 \\
1998 & 1173.3 & 1255.1 & 406.4 & 0.35 & 153 \\
1999 & 1150.0 & 1311.6 & 384.3 & 0.33 & 168 \\
2000 & 917.4 & 1220.4 & 336.6 & 0.37 & 172 \\
2001 & 516.5 & 810.5 & 234.0 & 0.45 & 132 \\
\hline
\end{tabular}

$\mathrm{N}$ denotes the number of villages and towns invaded, and Area ratio refers to the ratio of the invaded area to the total area of early rice fields
Table 2 Spread distance of $L$. oryzophilus in three primary directions from 1994 to 2001 within Zhejiang Province

\begin{tabular}{llll}
\hline Year & $\begin{array}{l}\text { Spread distance } \\
\text { southwestward } \\
(\mathrm{km})\end{array}$ & $\begin{array}{l}\text { Spread distance } \\
\text { northeastward } \\
(\mathrm{km})\end{array}$ & $\begin{array}{l}\text { Spread distance } \\
\text { northwestward } \\
(\mathrm{km})\end{array}$ \\
\hline 1994 & 90.68 & 10.32 & 0 \\
1995 & 0 & 22.68 & 2.98 \\
1996 & 0 & 22.08 & 13.68 \\
1997 & 0 & 28.76 & 0 \\
1998 & 0 & 60.26 & 6.86 \\
1999 & 0 & 58.80 & 33.69 \\
2000 & 0 & 0 & 0 \\
2001 & 0 & -1.65 & -12.12 \\
\hline
\end{tabular}

The minus sign denotes a reduction in the invaded area from the previous year

the landscape. For each transect, PLAND tended to decrease in the inland direction as the distance away from the coast increased although fluctuations did exist (Figs. 3, 4a).Each transect had at least one grid cell with a rather low value of PLAND. The values of MPS for the six transects exhibited a roughly similar pattern to that of PLAND (Fig. 4b).

Also at the $20 \times 20 \mathrm{~km}$ window size, the average value of CONNECT for the six transects was $5.5 \%$, and $91.7 \%$ of the grid cells had values smaller than $10 \%$. These results indicated a low degree of overall connectivity among rice paddies in the landscape. For most of the six transects, CONNECT tended to decline toward the inland direction and reached zero at least once at a certain distance (Fig. 4c). Because each grid cell had a side length of $20 \mathrm{~km}$, this means that there were unconnected spaces of at least $20 \mathrm{~km}$ in each of the 5 transects (except for transect 5 ), which are much greater than the flight distance of $2 \mathrm{~km}$ for L. oryzophilus. The connectivity of transects 2 and 6 decreased first and then increased toward the inland end of the grids (Fig. 4c).

At the $10 \times 10 \mathrm{~km}$ window size, the three landscape metrics exhibited similar patterns along the transects to those at the $20 \times 20 \mathrm{~km}$ window size, but with considerably greater variations (Fig. 4d-f). Reducing the window size resulted in much greater changes in the values of $\mathrm{CON}$ NECT than those of PLAND and MPS along the transects. These results at the two window sizes together, however, seemed to confirm two findings: PLAND and MPS tended to decrease toward the inland area, and CONNECT fluctuated more than PLAND and MPS, reaching the value of zero at certain distances. In particular, the number of grid cells with zero connectivity increased considerably at the smaller window size. 

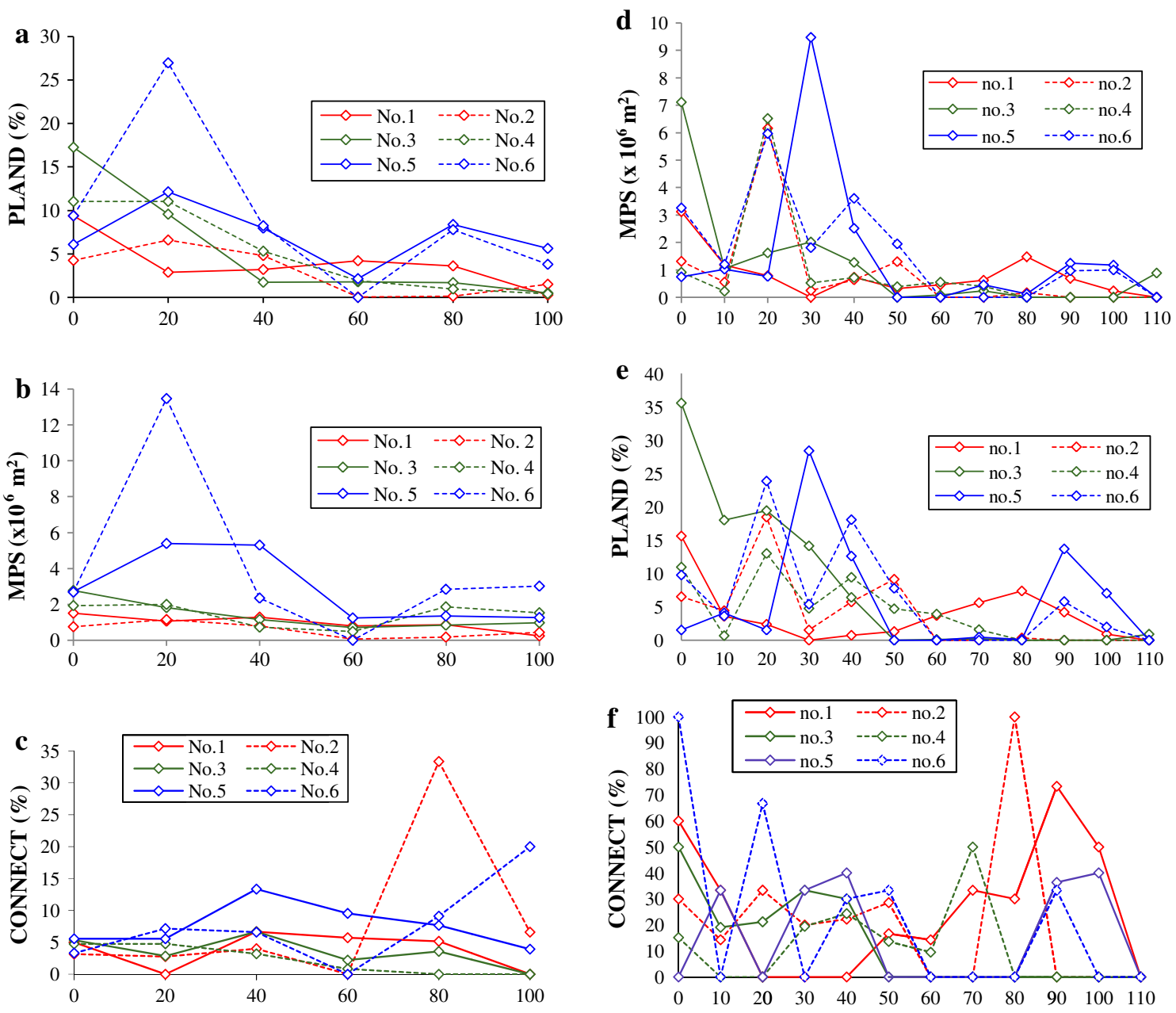

Distance from the center of the first grid cell located at the costal end ( grid cell size $=20 \times 20 \mathrm{~km}$ )

Distance from the center of the first grid cell located at the costal end $($ grid cell size $=10 \times 10 \mathrm{~km})$

Fig. 4 Changes in landscape metrics-PLAND, MPS and CONNECT_-from coastal to inland areas. Although only data in 1999 were available, the spatial distribution of the early rice fields remained similar throughout the study period

\section{Discussion}

Spatial Pattern and Determinants of the L. oryzophilus Spread

Our analysis showed that the rice water weevil rapidly invaded a broad area of early rice fields in Zhejiang Province between 1993 and 2001. The directions of the spread from the localities in 1993 were primarily northeastward and southwestward along the coastal areas. The spread toward the inland areas was quite limited although there were a large number of early rice paddies further west of the already invaded areas. This particular spread pattern requires explanation, and identifying its underlying causes will help us better understand pest spread dynamics and thus develop more effective management strategies.
A number of studies have shown that the spread of invasive species across a heterogeneous landscape is affected by the spatial pattern of habitat (With 2002; Maheu-Giroux and Blois 2007; Zhu and others 2007; Sebert-Cuvillier and others 2008; Thiele and others 2008).In particular, the distance between habitat patches and the mobility of a species together play a critically role in spread dynamics. Our study suggests that the composition and spatial arrangement of types of land covers were important determinants of the spatial pattern of the rice water weevil invasion. The most important of all seemed to be the connectivity of early planted rice paddies.

The dispersal ability of $L$. oryzophilus is quite limited, and its longest migratory flight is known to be less than $2 \mathrm{~km}$ in this region (Zhai and others 1997).Also, the pest only attempts to fly under calm weather conditions (mostly 
Fig. 5 Topography and major road network of Zhejiang Province

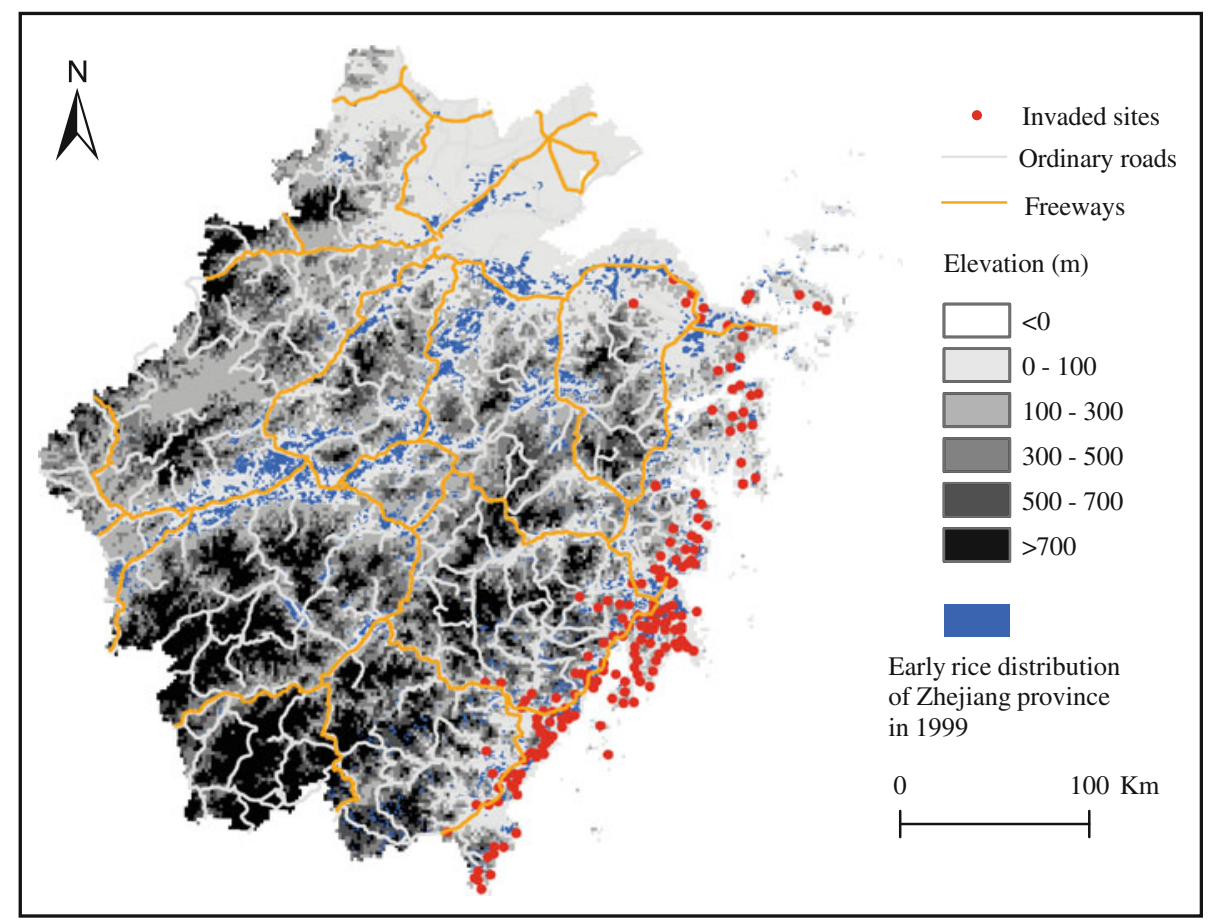

after sunset) (Zhai and others 1999).Moreover, mountains and hills widely present in the study area are barriers to the long-distance migration of the pest. Although a small number of $L$. oryzophilus fly a few tens of meters high, they usually cannot disperse far from local habitats even with strong winds (Zhai and others 1997, 1999).Thus, a high degree of habitat connectivity is necessary for the pest to spread over broad areas. We used three landscape indices (PLAND, MPS, and CONNECT) to quantify the amount, size, and connectivity of habitat patches for the rice water weevil. Although they are correlated to each other (in other words, higher PLAND results in higher MPS and greater CONNECT), the three indices each provide additional information on the habitat pattern, and landscapes. For example, similar PLAND and MPS may have quite different values of CONNECT due to differences in spatial arrangement of habitat patches (Wu and others 2002; Wu 2004).All three indices indicated that the habitat connectivity for the pest decreased from costal to inland areas. For a migratory insect like L. oryzophilus, inter-patch distance is less of an obstacle as long as it is within its maximum flight distance. However, our transect analysis showed that non-habitat gaps existed whose sizes were much larger than the maximum dispersal distance of the pest. Thus, the overall low level of habitat connectivity and the existence of large non-habitat gaps probably make it exceedingly difficult, if not impossible, for the rice water weevil to travel long-distance toward the inland areas.

A few other factors may also have played a role in influencing the spatial pattern of the pest invasion. Forests (specifically understory herbaceous and litter) and grasses on the mountains close to the rice paddies are the main aestivation and overwintering habitat of L. oryzophilus in the study area (Yu 2000; Gu and others 2002; Lin and Zhao 1998). The insect usually has two migration periods between early-rice paddies and overwintering habitat each year. During April and May, the adults that have survived the past winter migrate from overwintering habitat to the early-rice paddies ( $\mathrm{Gu}$ and others 2002), and from June to July most of the first generation adults migrate from the early-rice paddies to mountains for aestivation, and then directly enter into the state of overwintering after autumn (Lin and Zhao 1998; Zhai and others 1997).Therefore, the forest itself cannot serve as a corridor to promote the longdistance spread of the invasive insect. In fact, large tracts of forests on the mountains west of the invaded areas may have helped impede the spread of L. oryzophilus towards the inland areas. As they are not suitable habitat for rice water weevil, little damage has been observed in the forests.

Crop fields other than rice paddies can also disrupt the connectivity between rice paddies, but their effect was not likely to be significant simply because of their rather limited distribution (Zhejiang Provincial Bureau of Forestry 2002).In addition, there were several freeways that ran through these mountains to connect the coastal and inland areas (Fig. 5).The population of the L. oryzophilus seemed to have a tendency to spread along the roads. For example, some studies found that L. oryzophilus can disperse with transportation by sticking to the seedling, straw, rice seeds, rice shell, or parts of vehicle (Cai and others 1997; Zhang 
1997).However, our study showed that the spread of the rice water weevil along road corridors was rather limited in our study region.

\section{Implications for Management}

To control the spread of the invasive species $L$. oryzophilus, we suggest four management measures based on our study:

(1) Implement a landscape-level planning scheme of cropping systems to minimize the area and connectivity of suitable habitat for the pest. Double-cropping of rice has been widely practiced in Zhejiang Province. The planting time for early rice is earlier than both late rice and single cropping rice. Connected rice fields form corridors that accelerate the spread of $L$. oryzophilus, and this pest would find it difficult to survive and spread in single-cropping rice fields because of unsuitable habitat and food shortage surrounding them. Our analysis indicated that the invaded area was also significantly correlated with the late rice area of the previous year $(r=0.89$, one-tailed probability $=0.002$ ), suggesting that late rice fields enable the insect to live through rice growing seasons and spread across the landscape. Thus, extending the area of singlecropping rice fields and isolating early-rice paddies by a distance at least several times larger than the maximum flight distance of the pest (i.e., $2 \mathrm{~km}$ ) may greatly reduce the probability of invasive spreading.

(2) Control the damage within the invaded areas through biological, physical and chemical methods as appropriate, and to reduce the source populations of the insects. It is essential to use integrated methods of prevention and control to eliminate local source populations and contain their spread into the unaffected neighboring locations. These local-scale measures, however, would not be effective without proper planning at the landscape scale.

(3) Monitor the temporal change and spatial pattern of the pest spread seasonally and provide early warning forecast. Continuous monitoring and timely reporting by local agricultural stations are critically important for effective actions against the rapid spread of the pest population. It is particularly crucial to pay special attention to those areas within and near infected locations and along transportation corridors.

(4) Strengthen the quarantine system which is an effective way to cut off the source and spread routes. With the development of international trade and transportation systems, there are increasing opportunities for the invasive species to spread, making it more difficult to control. A comprehensive and rigorously maintained quarantine system is still one of the most effective approaches to preventing pest spread over broad scales, especially with contaminated vehicles and goods from invasive areas.
None of the above measures alone would eliminate or sustainably restrain the population of the rice water weevil in the study region. To successfully contain the spread of the pest population, all four management approaches need to be implemented together in an integrated way. Our study, as a specific case, demonstrates a general need for a multi-scaled and multi-dimensional approach that is essential for controlling the spread of invasive species and infectious diseases in many parts of the world ( $\mathrm{Lu}$ and others 2007; Crowl and others 2008).

Acknowledgments We are grateful to the local monitoring stations of Zhejiang Province for sharing their historical data on the invasion of $L$. oryzophilus, to Z. Shi and J.F. Huang for help with the maps of rice paddies, and to Tracy Shoumaker and the two anonymous reviewers for their helpful comments on an earlier version of the manuscript. This research was supported by grants from Beijing Educational Committee (Grant No. KM200810028014) and the National Natural Science Foundation of China (Grant No. 30571241).

\section{References}

Andreassen HP, Halle S, Ims RA (1996) Optimal width of movement corridors for root voles: not too narrow and not too wide. Journal of Applied Ecology 33:63-70

Brett JG (2003) Is landscape connectivity a dependent or independent variable? Landscape Ecology 18:687-699

Brooker L, Brooker M, Cale P (1999) Animal dispersal in fragmented habitat: measuring habitat connectivity, corridor use, and dispersal mortality. Conservation Ecology 3:4

Cai Y, Liu SS, Song F, Wang X, Gao BZ, Chen HC (1997) Research on the spread of the rice water weevil in China (IV). Plant Quarantine 11:219-220 (in Chinese)

Chen H, Chen Z, Zhou Y (2005) Rice water weevil (Coleoptera: Curculionidae) in mainland China: invasion, spread and control. Crop Protection 24:695-702

Chinese National Agricultural Technical Extension Service Center (1998) Rice water weevil in China. China Agriculture Press, Beijing (in Chinese)

Clifford EK, Patrick JS, Alexander YK, Lyubov EB, Jeffrey CN, Ladd EJ, Dianna KP (2002) Landscape patterns of an aquatic invader: assessing dispersal extent from spatial distributions. Ecological Applications 12:749-759

Collinge SK (2000) Effects of grassland fragmentation on insect species loss, colonization, and movement patterns. Ecology 81:2211-2226

Crowl TA, Crist TO, Parmenter RR, Belovsky G, Lugo AE (2008) The spread of invasive species and infectious diseases as drivers of ecosystem change. Frontiers in Ecology and the Environment 6:238-246

Goh HG, Choi KM (1993) Forecasting methods of the rice water weevil in Korea. In: Hirai K (ed) Establishment, spread, and management of the rice water weevil and migratory rice pests in East Asia. NARC, Tsukuba, Japan, pp 133-162

Gu YQ, Lin YB, Yu JH (2002) Application and its effects on control and eradication technology for the rice weevil. Plant Protection 28:57-58 (in Chinese)

Guo YS (1996) Threat assessment of rice water weevil in Heibei, China and its quarantine strategies. Plant Quarantine 10:288-290 (in Chinese) 
Haddad N (2000) Corridor length and patch colonization by a butterfly, Junonia coenia. Conservation Biology 14:738-745

Iwata T (1976) Occurrence of the American rice water weevil in Japan. International Rice Research Newsletter 1:17

Li HB, Wu JG (2004) Use and misuse of landscape indices. Landscape Ecology 19:389-399

Lin YB, Zhao L (1998) Outbreak and control on the rice water weevil in Zhejiang Province, China. China Rice 4:22-24 (in Chinese)

Lu J, Wu J, Fu Z, Zhu L (2007) Water hyacinth in China: a sustainability science-based management framework. Environmental Management 40:823-830

Luck M, Wu J (2002) A gradient analysis of the landscape pattern of urbanization in the Phoenix metropolitan area of USA. Landscape Ecology 17:327-339

Maheu-Giroux M, Blois Sde (2007) Landscape ecology of Phragmites australis invasion in networks of linear wetlands. Landscape Ecology 22:285-301

McGarigal K, Cushman SA, Neel MC, Ene E (2002) FRAGSTATS: spatial pattern analysis program for categorical maps. Computer software program produced by the authors at the University of Massachusetts, Amherst. www.umass.edu/landeco/research/ fragstats/fragstats.html

Nesslage GM, Maurer BA, Gage SH (2007) Gypsy moth response to landscape structure differs from neutral model predictions: implications for invasion monitoring. Biological Invasions 9:585-595

Pither J, Taylor PD (1998) An experimental assessment of landscape connectivity. Oikos 83:166-174

Sebert-Cuvillier E, Simon-Goyheneche V, Paccaut F, Chabrerie O, Goubet O, Decocq G (2008) Spatial spread of an alien tree species in a heterogeneous forest landscape: a spatially realistic simulation model. Landscape Ecology 23:787-801

Shang HW, Zhai BP (1997) Invasion of rice water weevil towards Southern China and its control strategies. In: Yang XK (ed) Advance in entomology research. China Forestry Press, Beijing, China, pp 217-221 (in Chinese)

Shang HW, Cheng JA, Jiang MX, Tang QY, Gu YQ (2003) Survival of adult rice water weevils (Coleoptera: Curculionidae) during harvesting and storage of the first season rice crop in Zhejiang. Acta Entomologica Sinica 46:190-195 (in Chinese)

Thiele J, Schuckert U, Otte A (2008) Cultural landscapes of Germany are patch-corridor-matrix mosaics for an invasive megaforb. Landscape Ecology 23:453-465
Turner MG (1989) Landscape ecology: the effect of pattern on process. Annual Review of Ecology and Systematics 20:171-197

Wei HJ (1997) Occurrence posture and sustainable control of rice water weevil in China. Plant Quar 11(Suppl):60-62 (in Chinese)

Wiens JA, Schooley RL, Weeks RD Jr (1997) Patchy landscapes and animal movements: do beetles percolate? Oikos 78:257-264

With KA (2002) The landscape ecology of invasive spread. Conservation Biology 16:1192-1203

Wu JG (2004) Effects of changing scale on landscape pattern analysis: scaling relations. Landscape Ecology 19:125-138

Wu J (2009) Ecological dynamics in fragmented landscapes. In: Levin SA (ed) Princeton guide to ecology. Princeton University Press, Princeton, pp 438-444

Wu JG, Hobbs R (2002) Key issues and research priorities in landscape ecology: an idiosyncratic synthesis. Landscape Ecology 17:355-365

Wu JG, Shen WJ, Sun WZH, Tueller PT (2002) Empirical patterns of the effects of changing scale on landscape metrics. Landscape Ecology 17:761-782

$\mathrm{Yu}$ JH (2000) Cause and control measures for outbreak and population growth of the rice weevil in Huangyan, Zhejiang. Plant protection 26:39-40 (in Chinese)

Zhai BP, Cheng JA, Huang EY, Shang HW, Zheng XH, Wu J, Fang YJ, Xia WQ, Lü XJ (1997) Population dynamics of rice water weevil in double rice cropping area of Zhejiang Province, China. Scientia Agricultura Sinica 30(6):23-29 (in Chinese)

Zhai BP, Zheng XH, Shang HW, Cheng JA (1999) Influence of wind on takeoff of rice water weevils. Agricultural Meteorology Sinica 20:24-27 (in Chinese)

Zhang YJ (1997) Outbreak and control of the rice water weevil in Tanghai County. Plant Quarantine 11(1):240-241 (in Chinese)

Zhao CHD, Sun FY, Zhao WSH, Tian CHH (1996) Study on outbreak and control of the rice water weevil (1). Distribution and present status of rice water weevil outbreak in Liaoning Province. Liaoning Agricultural Sciences 5:8-11 (in Chinese)

Zhejiang Provincial Bureau of Forestry (2002) Zhejiang Forestry natural resources (forests volumes), 1st edn. China Agricultural Science and Technology Publishing House, Beijing (in Chinese)

Zhu L, Sun OJ, Sang WG, Li ZY, Ma KP (2007) Predicting the spatial distribution of an invasive plant species (Eupatorium adenophorum) in China. Landscape Ecology 22:1143-1154 